\title{
28 Research Square \\ Outcomes of COVID-19 in a cohort of pediatric patients with rheumatic diseases
}

\section{Diana Sofia Villacis-Nunez ( $\nabla$ dvillac@emory.edu )}

Emory University Department of Pediatrics https://orcid.org/0000-0001-9182-6067

\section{Christina A. Rostad}

Emory University Department of Pediatrics

\section{Kelly Rouster-Stevens}

Emory University Department of Pediatrics

\section{Arezou Khosroshahi}

Emory University School of Medicine

Shanmuganathan Chandrakasan

Emory University Department of Pediatrics

\section{Sampath Prahalad}

Emory University Department of Pediatrics

\section{Research article}

Keywords: Rheumatic diseases, COVID-19, pediatric rheumatology

Posted Date: January 18th, 2021

DOl: https://doi.org/10.21203/rs.3.rs-145918/v1

License: (c) (i) This work is licensed under a Creative Commons Attribution 4.0 International License. Read Full License 


\section{Abstract \\ Background}

There are few reports of COVID-19 in pediatric patients with rheumatic diseases. This study describes the clinical presentation and outcomes of COVID-19 in this population.

\section{Methods}

We analyzed a single-center case series of pediatric patients with rheumatic diseases and laboratoryconfirmed COVID-19. Demographic, baseline and COVID-19 associated clinical features were compared between ambulatory and hospitalized patients using univariate analysis.

\section{Results}

Forty cases were identified: $32(80 \%)$ in the ambulatory group and $8(20 \%)$ hospitalized. Older age (median age 18 years vs 16 years; $p=0.01$ ) and African American race (OR 8.42; 95\% Cl [1.20-101.69]; $p=$ $0.01)$ predominated in hospitalized patients. Systemic lupus erythematosus (OR 6.77; $95 \% \mathrm{Cl}[1.01-$ 56.71]; $p=0.02$ ), medium/high-dose corticosteroid use (OR 10.62; 95\% Cl [1.46-99.57]; $p=0.008)$, mycophenolate use (OR 11.91; 95\% Cl [1.64-149.35]; $p=0.005$ ), and severe immunosuppression (OR $16.83 ; 95 \% \mathrm{Cl}$ [1.74-861.43]; $p=0.004)$ were associated with increased odds of hospitalization. Patients with fever (OR 11.91; 95\% CI [1.64-149.35]; $\mathrm{p}=0.004$ ), dyspnea (OR 16.51; CI [1.10-998.37]; $\mathrm{p}=0.02$ ), and myalgias (OR 13.40; 95\% Cl [1.43-194.56)]; $p=0.009$ ) were more commonly encountered in the hospitalized group. Rheumatic disease flares were almost exclusive to hospitalized patients (OR 42.13; 95\% Cl [3.40-2463.87]; $p<0.001) .$. All patients recovered.

\section{Conclusions}

Medium/high-dose corticosteroid use, mycophenolate use, and severe immunosuppression were risk factors for hospitalization. Fever, dyspnea and myalgias were high-risk symptoms. The type of rheumatic disease, as well as disease flare could be contributing factors to the need for hospitalization.

\section{Background:}

COVID-19 results from infection with SARS-CoV-2, a novel coronavirus, and has been reported to have a milder disease course in children compared to adults. $(1,2)$ However, the known susceptibility to infections in patients with rheumatic diseases has been of great concern for pediatric rheumatologists during the pandemic. $(3,4)$ Outcomes from the largest case series of adults with rheumatic diseases reported $91 \%$ survival, despite a $50 \%$ hospitalization rate.(5) Although some studies of COVID-19 in rheumatic disease patients include a few pediatric cases, with overall favorable outcomes, pediatric data 
remain scarce.(6-9) The aim of our study was to analyze the clinical presentation and outcomes of COVID-19 in a case series of pediatric patients with rheumatic diseases, and to identify risk factors associated with adverse outcomes.

\section{Methods:}

Pediatric patients ( $0-21$ years) with rheumatic diseases followed at Children's Healthcare of Atlanta $(\mathrm{CHOA})$ in the state of Georgia and laboratory-confirmed SARS-CoV-2 infection from May 2020 to November 2020 were retrospectively identified. Diagnosis was established either through patient/family report of positive SARS-CoV-2 test or by positive nasopharyngeal polymerase chain reaction (PCR) test performed at CHOA. The present study was approved by the Institutional Review Board (IRB) at CHOA via waiver of informed consent (IRB number STUDY00000771).

Cases were classified into two groups based on need for hospitalization. Demographic (age, sex, race/ethnicity), and clinical data (baseline rheumatic disease diagnosis/activity, comorbidities, medications, degree of immunosuppression, COVID-19 exposure/symptoms, immunosuppression management, and outcomes) were collected through chart review.

Rheumatic disease activity was assessed using the Systemic Lupus Erythematosus Disease Activity Index-2000 (SLEDAI-2K) and Juvenile Arthritis Disease Activity Score (JADAS) when indicated. If unable to calculate, physician assessment of disease activity was utilized. Active disease was defined as a SLEDAI-2K score $\geq 6$, JADAS-10 score $>1$, or rheumatologist assessment indicating active disease.

The level of immunosuppression was defined as severe if the subject reported use of one or more of: intravenous (IV) cyclophosphamide (within 3 months), rituximab (within 6 months), medium/high-dose ( $\geq 10 \mathrm{mg} /$ day) oral corticosteroids (CS), outpatient IV CS. Patients on immunomodulators not meeting these criteria were considered mild to moderately immunosuppressed.

Demographic and clinical features were compared between groups using Fisher exact test (with corresponding Odds ratios (OR) and $95 \%$ confidence intervals $(\mathrm{Cl})$ ) for categorical variables, and Mann-UWhitney test for continuous variables, employing $R$ software. $P$ values $\leq 0.05$ were considered statistically significant.

\section{Results:}

\section{Patient cohort, demographics, and baseline clinical features:}

Forty cases were identified: 8 (20\%) required hospitalization, and $32(80 \%)$ received ambulatory care. Demographics are outlined in Table 1. Patients in the hospitalized group were significantly older than patients in the ambulatory group (median age 18 years vs 16 years; $p=0.01$ ). The racial and ethnic distribution differed between groups: a higher proportion of African American patients were encountered 
in the hospitalized group (OR 8.42, 95\% $\mathrm{Cl}$ [1.20-101.69]; $\mathrm{p}=0.01$ ), while Caucasian patients predominated in the ambulatory group (OR $0.11,95 \% \mathrm{Cl}[0.002-1.08] ; \mathrm{p}=0.05)$. 
Table 1

Demographic and baseline clinical features

\begin{tabular}{|c|c|c|c|c|c|c|c|c|}
\hline Category & \multicolumn{2}{|c|}{$\begin{array}{l}\text { Total } \\
n=40\end{array}$} & \multicolumn{2}{|c|}{$\begin{array}{l}\text { Hospitalized } \\
n=8\end{array}$} & \multicolumn{2}{|c|}{$\begin{array}{l}\text { Ambulatory } \\
n=32\end{array}$} & \multirow[t]{2}{*}{$\begin{array}{l}\text { OR } \\
(95 \% \mathrm{Cl})\end{array}$} & \multirow[t]{2}{*}{$\mathbf{P}$} \\
\hline \multicolumn{7}{|l|}{ Demographics } & & \\
\hline Age in years & 16 & $\begin{array}{l}(14- \\
18)\end{array}$ & 18 & $\begin{array}{l}(16.75- \\
19)\end{array}$ & 16 & $\begin{array}{l}(13.75- \\
17)\end{array}$ & & 0.01 \\
\hline Female & 31 & $(77.5)$ & 6 & $(75)$ & 25 & $(78.1)$ & $\begin{array}{l}0.84(0.11- \\
10.34)\end{array}$ & 1 \\
\hline African American & 14 & $(85)$ & 6 & $(75)$ & 8 & $(25)$ & $\begin{array}{l}8.42(1.20- \\
101.69)\end{array}$ & 0.01 \\
\hline Asian & 1 & $(2.5)$ & 0 & $(0)$ & 1 & (3.1) & $0(0-155.62)$ & 1 \\
\hline Caucasian & 19 & $(47.5)$ & 1 & $(12.5)$ & 18 & $(56.3)$ & $\begin{array}{l}0.11(0.002- \\
1.08)\end{array}$ & 0.05 \\
\hline Hispanic or Latino & 6 & $(15)$ & 1 & $(12.5)$ & 5 & $(15.6)$ & $\begin{array}{l}0.77(0.014- \\
8.83)\end{array}$ & 1 \\
\hline \multicolumn{9}{|c|}{ Baseline clinical features } \\
\hline Comorbidities & 25 & $(62.5)$ & 6 & $(75)$ & 19 & $(59.4)$ & $\begin{array}{l}2.02(0.29- \\
23.49)\end{array}$ & 0.68 \\
\hline \multicolumn{9}{|c|}{ Primary rheumatic disease } \\
\hline $\begin{array}{l}\text { Juvenile Idiopathic } \\
\text { arthiritis }\end{array}$ & 12 & $(30)$ & 1 & $(12.5)$ & 11 & $(34.4)$ & $\begin{array}{l}0.28(0.006- \\
2.67)\end{array}$ & 0.39 \\
\hline $\begin{array}{l}\text { Systemic lupus } \\
\text { erythematosus }\end{array}$ & 11 & $(27.5)$ & 5 & $(62.5)$ & 6 & $(18.8)$ & $\begin{array}{l}6.77(1.01- \\
56.71)\end{array}$ & 0.02 \\
\hline $\begin{array}{l}\text { Juvenile } \\
\text { Dermatomyositis }\end{array}$ & 5 & $(12.5)$ & 0 & $(0)$ & 5 & $(15.6)$ & $0(0-4.54)$ & 0.56 \\
\hline Other & 11 & $(27.5)$ & 2 & $(25)$ & 9 & $(28.1)$ & $\begin{array}{l}0.85(0.07- \\
6.08)\end{array}$ & 1 \\
\hline $\begin{array}{l}\text { Active rheumatic } \\
\text { disease }\end{array}$ & 22 & (55) & 7 & (87.5) & 15 & $(46.9)$ & $\begin{array}{l}7.58(0.82- \\
377.32)\end{array}$ & 0.05 \\
\hline
\end{tabular}

Numerical variables are expressed as median (IQR), and categorical variables as $\mathrm{n}(\%)$.

Abbreviations: Cl: Confidence Interval; bDMARDs: biologic disease modifying anti-rheumatic drugs; cDMARDs: conventional disease modifying anti-rheumatic drugs; OR: Odds ratio; IQR: Interquartile

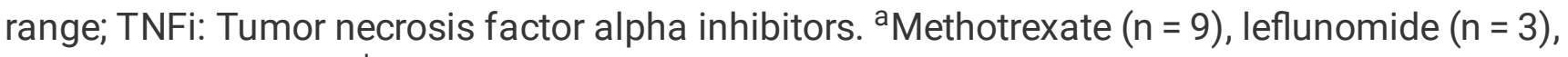
sulfasalazine $(n=1) \cdot{ }^{\text {b}}$ Abatacept $(n=3)$, tocilizumab $(n=2)$, ustekinumab $(n=1)$, anakinra $(n=1)$. $c_{n=37}$ : Patients off immunomodulators excluded. 


\begin{tabular}{|c|c|c|c|c|c|c|c|c|}
\hline \multirow{2}{*}{$\begin{array}{l}\text { Category } \\
\text { Oral corticosteroids }< \\
10 \mathrm{mg}\end{array}$} & \multicolumn{2}{|c|}{$\begin{array}{l}\text { Total } \\
\mathrm{n}=\mathbf{4 0}\end{array}$} & \multicolumn{2}{|c|}{$\begin{array}{l}\text { Hospitalized } \\
n=8\end{array}$} & \multicolumn{2}{|c|}{$\begin{array}{l}\text { Ambulatory } \\
n=32\end{array}$} & \multirow{2}{*}{$\begin{array}{l}\text { OR } \\
(95 \% \mathrm{Cl}) \\
3.10(0.21- \\
34.04)\end{array}$} & \multirow{2}{*}{$\begin{array}{l}\mathbf{P} \\
0.26\end{array}$} \\
\hline & 5 & $(12.5)$ & 2 & $(25.0)$ & 3 & (9.4) & & \\
\hline $\begin{array}{l}\text { Oral corticosteroids } \\
\geq 10 \mathrm{mg}\end{array}$ & 9 & $(22.5)$ & 5 & $(62.5)$ & 4 & $(12.5)$ & $\begin{array}{l}10.62(1.46- \\
99.57)\end{array}$ & 0.008 \\
\hline IV pulse corticosteroids & 3 & $(7.5)$ & 0 & $(0.0)$ & 3 & (9.4) & $0(0-10.20)$ & 1 \\
\hline Hydroxychloroquine & 22 & $(55.0)$ & 6 & $(75.0)$ & 16 & $(50.0)$ & $\begin{array}{l}2.92(0.43- \\
33.87)\end{array}$ & 0.26 \\
\hline Other cDMARDs ${ }^{a}$ & 13 & $(32.5)$ & 1 & $(12.5)$ & 12 & $(37.5)$ & $\begin{array}{l}0.24(0.005- \\
2.31)\end{array}$ & 0.2 \\
\hline Mycophenolate & 12 & $(30.0)$ & 6 & $(75.0)$ & 6 & $(18.8)$ & $\begin{array}{l}11.91(1.64- \\
149.35)\end{array}$ & 0.005 \\
\hline Tofacitinib & 2 & $(5.0)$ & 1 & $(12.5)$ & 1 & (3.1) & $\begin{array}{l}4.2(0.05- \\
357.33)\end{array}$ & 0.36 \\
\hline $\begin{array}{l}\text { Intravenous } \\
\text { immunoglobulin }\end{array}$ & 4 & $(10.0)$ & 0 & $(0.0)$ & 4 & $(12.5)$ & $0(0-6.38)$ & 0.57 \\
\hline Cyclophosphamide & 4 & $(10.0)$ & 1 & $(12.5)$ & 3 & $(9.4)$ & $\begin{array}{l}1.36(0.02- \\
20.35)\end{array}$ & 1 \\
\hline TNFi & 7 & $(17.5)$ & 0 & $(0.0)$ & 7 & $(21.9)$ & $0(0-2.76)$ & 0.31 \\
\hline Rituximab & 5 & $(12.5)$ & 3 & $(37.5)$ & 2 & (6.3) & $\begin{array}{l}8.28(0.76- \\
123.37)\end{array}$ & 0.05 \\
\hline Other bDMARDs $s^{b}$ & 7 & $(17.5)$ & 1 & $(12.5)$ & 6 & $(18.8)$ & $\begin{array}{l}0.62(0.01- \\
6.71)\end{array}$ & 1 \\
\hline None & 3 & $(7.5)$ & 0 & $(0.0)$ & 3 & (9.4) & $0(0-10.20)$ & 1 \\
\hline $\begin{array}{l}\text { Severe } \\
\text { Immunosupression }^{c}\end{array}$ & 15 & $(40.5)$ & 7 & $(87.5)$ & 8 & $(27.6)$ & $\begin{array}{l}16.83(1.74- \\
861.43)\end{array}$ & 0.004 \\
\hline \multicolumn{9}{|c|}{ Numerical variables are expressed as median (IQR), and categorical variables as $\mathrm{n}(\%)$. } \\
\hline \multicolumn{9}{|c|}{ 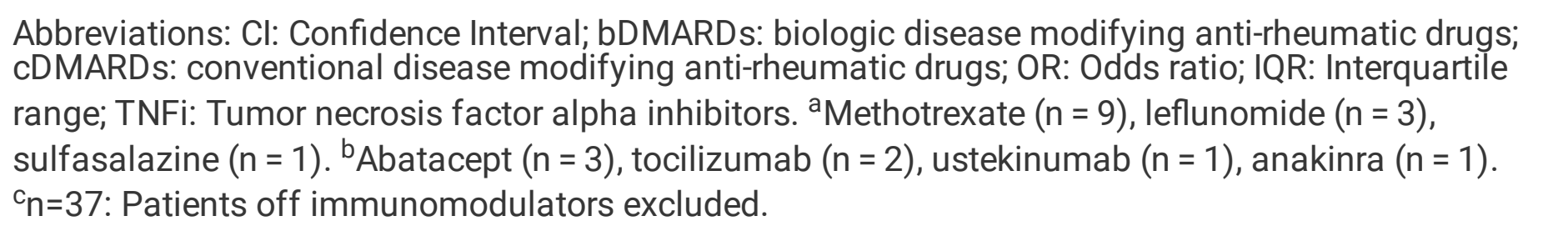 } \\
\hline
\end{tabular}

Table 1 details baseline clinical features. The frequency of underlying comorbidities was comparable between groups. Reported comorbidities consisted of: asthma $(n=6)$, hypertension $(n=5)$, lupus nephritis $(n=5)$, restrictive/interstitial lung disease $(n=4)$, obesity $(n=4)$, anemia of chronic disease $(n=2)$, inflammatory bowel disease $(n=3)$, and one patient each had pulmonary hypertension, end-stage renal 
disease on chronic dialysis, post-renal transplant status, left ventricular hypertrophy, chronic diarrhea, cholestasis, esophageal dysmotility, adrenal insufficiency, hyperparathyroidism, hypothyroidism, thyroid disease, chronic neutropenia, sickle cell disease, recurrent infections, immunoglobulin G deficiency, and Wilms tumor. Patients with cardiovascular disease, namely left ventricular hypertrophy and hypertension, were more likely to be in the hospitalized group (OR 8.28, 95\% $\mathrm{Cl}$ [0.76-123.37]; $p=0.05]$. No significant differences were observed regarding the presence of the remaining specific comorbidities between groups.

Juvenile idiopathic arthritis (JIA), systemic lupus erythematosus (SLE), and juvenile dermatomyositis (JDM) were the most common primary rheumatic diagnoses among children with COVID-19.

Undifferentiated connective tissue disease $(n=3)$, idiopathic uveitis $(n=3)$, Takayasu's arteritis $(n=1)$, overlap syndrome $(n=1)$, systemic scleroderma $(n=1)$, Behcet's disease $(n=2)$ and sarcoidosis $(n=1)$ were also identified as primary rheumatic diagnoses. Four patients had an additional rheumatic comorbidity: SLE + rheumatoid arthritis $(n=1), S L E+$ macrophage activation syndrome $(n=2), J I A+$ Sjogren's syndrome $(n=1)$. SLE was observed more frequently in the hospitalized group $(O R 6.77,95 \% \mathrm{Cl}$ [1.01-56.71]; $p=0.02)$. Similarly, active disease was more commonly encountered in the hospitalized group (OR 7.58, 95\% Cl [0.82-377.32]; $p=0.05$ ).

The majority of patients in both groups were taking at least one immunomodulatory medication, as detailed in Table 1. Besides those, additional immunosuppressants used in the ambulatory group included cyclosporine $(n=1)$, tacrolimus $(n=1)$, and colchicine $(n=1)$. NSAID use was observed in 5 (62.5\%) patients in the hospitalized group and $14(43.8 \%)$ patients in the ambulatory group $(p=0.44)$. The use of medium/high-dose CS (OR 10.62; 95\% Cl [1.46-99.57]; $p=0.008)$, mycophenolate (OR 11.91; $95 \% \mathrm{Cl}[1.64-149.35] ; \mathrm{p}=0.005)$ and rituximab (OR 8.28; 95\% $\mathrm{Cl}[0.76-123.37] ; \mathrm{p}=0.05)$ increased the odds of hospitalization. No patients using tumor necrosis factor-alpha inhibitors (TNFi), intravenous immunoglobulin (IVIG) or IV pulse CS were hospitalized. No significant differences regarding use of other DMARDs were observed. Severely immunosuppressed individuals had increased odds of hospitalization (OR 16.83; 95\% Cl [1.74-861.43]; $p=0.004)$.

\section{COVID-19 exposure, symptoms and diagnosis:}

Table 2 lists symptoms and COVID-19 exposure history. Patients with fever, dyspnea, and myalgias had increased odds of hospitalization ( $p<0.05$ for each comparison). 
Table 2

COVID-19 exposure and symptoms

\begin{tabular}{|c|c|c|c|c|c|c|c|c|}
\hline \multirow{2}{*}{$\begin{array}{l}\text { Category } \\
\text { COVID-19 exposure }\end{array}$} & \multicolumn{2}{|c|}{$\begin{array}{l}\text { Total } \\
n=40\end{array}$} & \multicolumn{2}{|c|}{$\begin{array}{l}\text { Hospitalized } \\
n=8\end{array}$} & \multicolumn{2}{|c|}{$\begin{array}{l}\text { Ambulatory } n \\
=32\end{array}$} & \multirow{2}{*}{$\begin{array}{l}\text { OR } \\
(95 \% \mathrm{Cl}) \\
0.53(0.07- \\
3.32)\end{array}$} & \multirow{2}{*}{$\begin{array}{l}P \\
0.69\end{array}$} \\
\hline & 20 & $(50.0)$ & 3 & $(37.5)$ & 17 & $(53.1)$ & & \\
\hline \multicolumn{9}{|l|}{ Symptoms } \\
\hline Fever & 12 & $(30.0)$ & 6 & $(75.0)$ & 6 & $(18.8)$ & $\begin{array}{l}11.91(1.64- \\
149.35)\end{array}$ & 0.004 \\
\hline Rinorrhea/Congestion & 8 & $(20.0)$ & 1 & $(12.5)$ & 7 & $(21.9)$ & $\begin{array}{l}0.52(0.01- \\
5.33)\end{array}$ & 1 \\
\hline Cough & 15 & $(37.5)$ & 3 & $(37.5)$ & 12 & $(37.5)$ & $1(0.13-6.28)$ & 1 \\
\hline Dyspnea & 4 & $(10.0)$ & 3 & $(37.5)$ & 1 & (3.1) & $\begin{array}{l}16.51 \text { (1.10- } \\
998.37)\end{array}$ & 0.02 \\
\hline Chest pain & 3 & $(7.5)$ & 2 & $(25.0)$ & 1 & (3.1) & $\begin{array}{l}9.46(0.43- \\
625.27)\end{array}$ & 0.1 \\
\hline Myalgias & 6 & $(15.0)$ & 4 & $(50.0)$ & 2 & (6.3) & $\begin{array}{l}13.40(1.43- \\
194.56)\end{array}$ & 0.009 \\
\hline Abdominal pain & 3 & $(7.5)$ & 1 & $(12.5)$ & 2 & (6.3) & $\begin{array}{l}2.09(0.03- \\
45.87)\end{array}$ & 0.5 \\
\hline Anorexia/Nausea/Emesis & 7 & $(17.5)$ & 2 & $(25.0)$ & 5 & $(15.6)$ & $\begin{array}{l}1.77(0.13- \\
14.69)\end{array}$ & 0.61 \\
\hline Diarrhea & 9 & $(22.5)$ & 3 & $(37.5)$ & 6 & $(18.8)$ & $\begin{array}{l}2.53(0.31- \\
18.00)\end{array}$ & 0.35 \\
\hline Anosmia/Ageusia & 10 & $(25.0)$ & 2 & $(25.0)$ & 8 & $(25.0)$ & $1(0.08-7.27)$ & 1 \\
\hline Rash & 3 & $(7.5)$ & 2 & $(25.0)$ & 1 & (3.1) & $\begin{array}{l}9.46(0.43- \\
625.27)\end{array}$ & 0.1 \\
\hline Fatigue/Malaise & 9 & $(22.5)$ & 1 & $(12.5)$ & 8 & $(25.0)$ & $\begin{array}{l}0.44(0.008- \\
4.36)\end{array}$ & 0.65 \\
\hline Sore throat & 7 & $(17.5)$ & 1 & $(12.5)$ & 6 & $(18.8)$ & $\begin{array}{l}0.62(0.01- \\
6.71)\end{array}$ & 1 \\
\hline Headache & 8 & $(20.0)$ & 1 & $(12.5)$ & 7 & $(21.9)$ & $\begin{array}{l}0.52(0.01- \\
5.33)\end{array}$ & 1 \\
\hline Asymptomatic & 8 & $(20.0)$ & 0 & $(0.0)$ & 8 & $(25.0)$ & $0(0-2.27)$ & 0.17 \\
\hline
\end{tabular}


Eight patients (20\%) were asymptomatic, all in the ambulatory group. Of those, one patient had a lung infiltrate in a surveillance chest tomography for metastatic Wilms tumor, prompting SARS-CoV-2 testing.

Nine patients had confirmatory PCR testing performed at CHOA; the rest were diagnosed at an outside facility. Of the 8 hospitalized patients, two were known to be SARS-CoV-2 positive prior to admission: the first patient was symptomatic and tested one week earlier, with subsequent worsening clinical status requiring hospitalization; for the second patient, PCR test results became available while still in the emergency room.

COVID-19 diagnosis was reported to rheumatology during the acute infection period in 20 (62.5\%) ambulatory and 7 ( $87.5 \%)$ hospitalized patients; the report was delayed by up 3 months for $12(37.5 \%)$ ambulatory patients, and by 6 weeks for 1 (12.5\%) patient admitted to an outside hospital.

\section{Complications, management and outcomes:}

Immunomodulatory management was comparable between groups (Table 3). In the ambulatory group, treatment was largely symptomatic. Inpatient therapies are detailed in Table 3. Overall, three patients (7.5\%) required Intensive Care Unit (ICU) admission for respiratory support with high-flow nasal cannula oxygen. 
Table 3

Complications, management and outcomes

\begin{tabular}{|c|c|c|c|c|c|c|c|c|}
\hline \multirow{2}{*}{$\begin{array}{l}\text { Category } \\
\begin{array}{l}\text { Rheumatic disease } \\
\text { flare }\end{array}\end{array}$} & \multicolumn{2}{|c|}{$\begin{array}{l}\text { Total } \\
\mathrm{n}=\mathbf{4 0}\end{array}$} & \multicolumn{2}{|c|}{$\begin{array}{l}\text { Hospitalized } \\
\mathrm{n}=\mathbf{8}\end{array}$} & \multicolumn{2}{|c|}{$\begin{array}{l}\text { Ambulatory } \\
\mathrm{n}=32\end{array}$} & \multirow{2}{*}{$\begin{array}{l}\text { OR } \\
(95 \% \mathrm{Cl}) \\
42.13(3.40- \\
2463.87)\end{array}$} & \multirow{2}{*}{$\begin{array}{l}\mathbf{P} \\
\\
<0.001\end{array}$} \\
\hline & 6 & $(15.0)$ & 5 & $(62.5)$ & 1 & $(3.1)$ & & \\
\hline \multicolumn{9}{|c|}{ Management of immunomodulators* } \\
\hline $\begin{array}{l}\text { Temporarily } \\
\text { discontinued }\end{array}$ & 13 & $(35.1)$ & 3 & $(37.5)$ & 10 & $(34.5)$ & $1.13(0.14-7.35)$ & 1 \\
\hline Continued & 24 & $(64.9)$ & 5 & $(62.5)$ & 19 & $(65.5)$ & & \\
\hline \multicolumn{9}{|l|}{ Inpatient therapies } \\
\hline ICU care & 3 & $(7.5)$ & 3 & $(37.5)$ & & NA & & \\
\hline Oxygen & 4 & $(10.0)$ & 4 & $(50.0)$ & & NA & & \\
\hline Hemodialysis & 1 & $(2.5)$ & 1 & $(12.5)$ & & NA & & \\
\hline \multicolumn{9}{|c|}{ COVID-19 specific therapies } \\
\hline Convalescent plasma & 2 & $(5.0)$ & 2 & $(25.0)$ & & NA & & \\
\hline Remdesivir & 2 & $(5.0)$ & 2 & $(25.0)$ & & NA & & \\
\hline Anticoagulation & 4 & $(10.0)$ & 4 & $(50.0)$ & & NA & & \\
\hline Intravenous antibiotics & 6 & $(15.0)$ & 6 & $(75.0)$ & & NA & & \\
\hline Length of stay in days & 4.5 & $\begin{array}{l}(2.5- \\
8)\end{array}$ & 4.5 & $\begin{array}{l}(2.5- \\
8)\end{array}$ & & NA & & \\
\hline $\begin{array}{l}\text { Re-admission (14 } \\
\text { days) }\end{array}$ & 1 & $(2.5)^{+}$ & 1 & $(12.5)$ & & NA & & \\
\hline Follow-up in days & $60(1$ & $7-88)$ & $\begin{array}{l}59( \\
73.2\end{array}$ & & $\begin{array}{l}62 \\
88)\end{array}$ & $.25-$ & & 0.95 \\
\hline \multicolumn{9}{|c|}{ Numerical variables are expressed as median (IQR), and categorical variables as $\mathrm{n}(\%)$. } \\
\hline \multicolumn{9}{|c|}{$\begin{array}{l}\text { Abbreviations: Cl: Confidence Interval; ICU: Intensive Care Unit; IQR: Interquartile range; OR: Odds ratio; } \\
\text { NA: Non-applicable. }\end{array}$} \\
\hline $\begin{array}{l}\text { * } n=37 \text { : Patients off imn } \\
\text { discharge for worsening } \\
\text { discharged } 3 \text { days later. }\end{array}$ & . & $\begin{array}{l}\text { ulators } \\
\text { poxia, }\end{array}$ & clud & $\begin{array}{l}{ }^{+} \mathrm{SL} \\
\text { kidne }\end{array}$ & & $\begin{array}{l}\text { re-adn } \\
\text { Recov }\end{array}$ & $\begin{array}{l}\text { ed } 6 \text { days after init } \\
\text { d without dialysis; }\end{array}$ & \\
\hline
\end{tabular}

Rheumatic disease flares were almost exclusive to hospitalized patients (OR 42.13; 95\% Cl [3.40-2463.87]; $p<0.001)$ and managed by increasing oral CS doses $(n=3)$, starting IV pulse CS $(n=4)$, and/or starting cyclophosphamide therapy $(n=1)$. One patient in the ambulatory group had a flare of gastrointestinal 
symptoms from Behcet's disease after holding adalimumab for 2 weeks; this was managed by restarting the medication.

In the ambulatory group, one patient with co-existent Group A Streptococcus infection was identified. Other complications, namely pneumonia $(n=3)$, acute kidney injury $(n=2)$, urosepsis $(n=1)$, and Clostridium difficile colitis $(n=1)$ were identified in hospitalized individuals. One patient with lupus nephritis flare needed hemodialysis. No patients required mechanical ventilation or died. No late complications, including multisystem inflammatory syndrome in children (MIS-C), were encountered after a median post-COVID-19 follow-up period of 60 days.

\section{Discussion:}

This study describes the presentation and outcomes of a cohort of pediatric patients with rheumatic diseases and laboratory-confirmed COVID-19. Overall, approximately $20 \%$ of our patients required hospitalization and $7.5 \%$ required ICU care. Although these rates are slightly higher than those reported in the general pediatric population, our study had a limited sample size relying mostly on voluntary reporting, and laboratory confirmation was required. $(10,11)$ As such, some milder cases may have gone unreported, and untested and/or asymptomatic cases were likely excluded. Additionally, severe COVID-19 has been linked to older pediatric age and African American race which were overrepresented in the hospitalized group. $(2,12)$ Cardiovascular disease has been identified as a risk factor for hospitalization in adults;(5) similarly, it was found more frequently in the hospitalized group in our cohort, potentially having influenced these patients' outcomes, even if the confidence interval for this association was wide. (5) Reassuringly, none of our patients required mechanical ventilation and there were no fatalities, supporting previous reports that patients with rheumatic diseases and COVID-19 overall recover well.(69)

Symptoms of acute COVID-19 were similar to those described in the general pediatric population. $(2,10$, 11) Symptom reporting in the hospitalized group may have been less subject to recall bias. Notably, while respiratory and gastrointestinal symptoms are typically attributable to acute infection, fever and myalgias are also features of rheumatic disease flares. Fever, myalgias, and dyspnea predominated in hospitalized patients; furthermore, patients with active rheumatic disease were more likely to be in the hospitalized group, although the strength of this association was weak. These observations suggests that the interplay between rheumatic disease activity and flare, and severe COVID-19 may influence the need for admission, as proposed by Ye et al.(6)

Interestingly, while all JDM patients were managed in the ambulatory setting, SLE diagnosis was associated with hospitalization, raising the possibility of disease type playing a role in the outcomes as well. Indeed, the pattern of immune activation in patients with severe COVID-19 has been recently described, and is reported to bear many similarities to active SLE.(13) Moreover, therapy and presence of comorbidities vary by disease, offering another possible explanation for this observation. 
Echoing the findings of Gianfrancesco et al., medium/high-dose corticosteroid use was associated with increased odds of hospitalization.(5) Similar associations were observed for mycophenolate and severe immunosuppression; the latter may have been driven by the effect of medium/high-dose steroid use or reflect the underlying disease and its severity. Patients receiving rituximab therapy were also more likely to be in the hospitalized group, although the confidence interval for this association was substantially wide. While mycophenolate use has not been reported to increase the hospitalization risk in adults, rituximab use was found to be associated with higher rates of hospitalization and death from COVID-19 in a small cohort of adult patients with rheumatic diseases.(14) Larger, multicenter studies are still in need to further investigate and confirm these findings.

Our results align with the reported inverse association of TNFi and hospitalization in adults with rheumatic diseases,(5) as none of our TNFi recipients were hospitalized. Similar observations were noted for IVIG and IV pulse CS users, a previously unreported trend. Despite these findings not reaching statistical significance, they merit further exploration. Therapy with other DMARDs or NSAIDs did not influence hospitalization status, comparable to adults. $(5,15)$

Importantly, management of immunomodulators did not significantly differ between groups. Withholding immunosuppression in patients with rheumatic diseases and symptomatic COVID-19 has been reinforced by the American College of Rheumatology (ACR).(16) Each case should be assessed individually, as both COVID-19 and rheumatic disease exacerbations entail risks for hospitalization, especially considering that disease flare usually warrants an increase in immunosuppression.

Our study's major strength is that, to our knowledge, this is the largest case series describing laboratoryconfirmed COVID-19 in pediatric patients with rheumatic diseases. Limitations include its retrospective nature, and the method of patient selection which precludes us from calculating incidence and obtaining generalizable conclusions regarding severity compared to children without rheumatic diseases. The relatively small sample size precluded us from testing for collinearity between variables and performing multivariable analyses. Despite these limitations, we were able to achieve our aim of conveying the outcomes of COVID-19 in a cohort of pediatric rheumatic disease patients, setting precedent for larger studies needed to confirm the potential associations described in this manuscript. Multicenter studies would be useful to more comprehensively define the spectrum of COVID-19 and its natural history in children with rheumatic diseases.

\section{Conclusions:}

In conclusion, the need for hospitalization for COVID-19 in this cohort of pediatric patients with rheumatic diseases was associated with older age, African American race, cardiovascular disease, activity and type of rheumatic disease, medium/high-dose prednisone use, mycophenolate use, rituximab use and severe immunosuppression. Fever, dyspnea and myalgias were high-risk symptoms which should be closely monitored when present. Decisions to continue or discontinue rheumatic disease therapy should be made on a case-by-case basis, following current ACR guidelines. 


\section{Abbreviations}

American College of Rheumatology: ACR

Children's Healthcare of Atlanta: CHOA

Confidence Interval: $\mathrm{Cl}$

Coronavirus Disease 19: COVID-19

Corticosteroids: CS

Disease modifying anti-rheumatic drugs: DMARDs

Institutional Review Board: IRB

Intensive Care Unit: ICU

Interquartile range: IQR

Intravenous: IV

Intravenous Immunoglobulin: IVIG

Juvenile Dermatomyositis: JDM

Juvenile Idiopathic Arthritis: JIA

Juvenile Arthritis Disease Activity Score: JADAS

Multisystem inflammatory syndrome in children: MIS-C

Non-Steroidal anti-inflammatories: NSAIDs

Odds ratio: $\mathrm{OR}$

Polymerase chain reaction: PCR

Severe Acute Respiratory Syndrome Coronavirus 2: SARS-CoV-2

Systemic lupus erythematosus: SLE

Systemic Lupus Erythematosus Disease Activity Index-2000: SLEDAI-2K

Tumor necrosis factor alpha inhibitors: TNFi

\section{Declarations}




\section{Ethics approval and consent to participate:}

The present study was approved by the Institutional Review Board (IRB) at CHOA via waiver of informed consent (IRB number STUDY00000771).

\section{Consent for publication:}

Not applicable.

\section{Availability of data and materials:}

The datasets used and/or analyzed during the current study are available from the corresponding author on reasonable request.

\section{Competing interests}

Dr. Rostad reports grants from BioFire, grants from Janssen, grants from Moderna, grants from Micron, grants from Medlmmune, grants from PaxVax, outside the submitted work; In addition, Dr. Rostad has a patent US20180333477A1 with royalties paid to Emory University.

Dr. Prahalad reports serving on a Macrophage Activation Syndrome Adjudication Committee for Novartis Pharmaceuticals. In addition, he was a consultant to Sigilon Therapeutics on immune mediated diseases. These have no bearing on the work reported herein.

The remaining authors have no conflicts of interest to declare.

\section{Funding}

Dr. Prahalad is supported in part, by the Marcus Foundation Inc., Atlanta. No additional funding was secured for this study.

\section{Authors' contributions}

DSVN and SP contributed to study design, data collection, data analysis; drafted and revised the manuscript critically for intellectual content and gave the final approval for the published version. KRS contributed to data collection and data analysis, revised the manuscript critically for intellectual content and gave the final approval for the published version. CAR, SC, and AK contributed to the study design and data analysis, revised the manuscript critically for intellectual content and gave the final approval for the published version.

\section{Acknowledgements}

We would like to thank Drs. Amit Thakral, Cynthia Manos, Elaine Flanagan, Angela Taneja, Baruch Goldberg, Omkar Phadke, Meghan Nelson and Sabina Kennedy for their contribution in the identification of cases. 


\section{References}

1. Shen Q, Guo W, Guo T, Li J, He W, Ni S, et al. Novel coronavirus infection in children outside of Wuhan, China. Pediatr Pulmonol. 2020;55(6):1424-9.

2. DeBiasi RL, Song X, Delaney M, Bell M, Smith K, Pershad J, et al. Severe Coronavirus Disease-2019 in Children and Young Adults in the Washington, DC, Metropolitan Region. J Pediatr. 2020;223:199-203 e1.

3. Danza A, Ruiz-Irastorza G. Infection risk in systemic lupus erythematosus patients: susceptibility factors and preventive strategies. Lupus. 2013;32:1286-94.

4. Beukelman T, Xie F, Chen L, Baddley JW, Delzell E, Grijalva CG, et al. Rates of hospitalized bacterial infection associated with juvenile idiopathic arthritis and its treatment. Arthritis Rheum. 2012;64(8):2773-80.

5. Gianfrancesco M, Hyrich KL, Al-Adely S, Carmona L, Danila MI, Gossec L, et al. Characteristics associated with hospitalisation for COVID-19 in people with rheumatic disease: data from the COVID19 Global Rheumatology Alliance physician-reported registry. Ann Rheum Dis. 2020;79(7):859-66.

6. Ye C, Cai S, Shen G, Guan H, Zhou L, Hu Y, et al. Clinical features of rheumatic patients infected with COVID-19 in Wuhan, China. Ann Rheum Dis. 2020;79(8):1007-13.

7. Michelena X, Borrell H, Lopez-Corbeto M, Lopez-Lasanta M, Moreno E, Pascual-Pastor M, et al. Incidence of COVID-19 in a cohort of adult and paediatric patients with rheumatic diseases treated with targeted biologic and synthetic disease-modifying anti-rheumatic drugs. Semin Arthritis Rheum. 2020;50(4):564-70.

8. Koker O, Demirkan FG, Kayaalp G, Cakmak F, Tanatar A, Karadag SG, et al. Does immunosuppressive treatment entail an additional risk for children with rheumatic diseases? A survey-based study in the era of COVID-19. Rheumatol Int. 2020;40(10):1613-23.

9. Filocamo G, Minoia F, Carbogno S, Costi S, Romano M, Cimaz R. Absence of severe complications from SARS-CoV-2 infection in children with rheumatic diseases treated with biologic drugs. J Rheumatol. 2020.

10. US Department of Health and Human Services/Centers for Disease Control and Prevention: CDC COVID-19 Response Team: Coronavirus Disease 2019 in Children - United States, February 12-April 2, 2020. Morbidity and Mortality Weekly Report. 2020;69(14).

11. Lu X, Zhang L, Du H, Zhang J, Li Y, Qu J, et al. SARS-CoV-2 Infection in Children. N Engl J Med. 2020 Apr 23;382(17):1663-5.

12. Gianfrancesco MA, Leykina LA, Izadi Z, Taylor T, Sparks JA, Harrison C, et al. Race/ethnicity association with COVID-19 outcomes in rheumatic disease: Data from the COVID-19 Global Rheumatology Alliance Physician Registry. Arthritis Rheumatol. 2020 Nov 3.

13. Woodruff MC, Ramonell RP, Nguyen DC, Cashman KS, Saini AS, Haddad NS, et al. Extrafollicular B cell responses correlate with neutralizing antibodies and morbidity in COVID-19. Nat Immunol. 2020;21:1506-16. 
14. Loarce-Martos J, Garcia-Fernandez A, Lopez-Gutierrez F, Garcia-Garcia V, Calvo-Sanz L, Del BosqueGranero I, et al. High rates of severe disease and death due to SARS-CoV-2 infection in rheumatic disease patients treated with rituximab: a descriptive study. Rheumatol Int. 2020;40(12):2015-21.

15. Scirè CA, Carrara G, Zanetti A, Landolfi G, Chighizola C, Alunno A, et al. COVID-19 in rheumatic diseases in Italy: first results from the Italian registry of the Italian Society for Rheumatology (CONTROL-19). Clin Exp Rheumatol. 2020;38:748-53.

16. Wahezi DM, Lo MS, Rubinstein TB, Ringold S, Ardoin SP, Downes KJ, et al. American College of Rheumatology Guidance for the Management of Pediatric Rheumatic Disease During the COVID-19 Pandemic: Version 1. Arthritis Rheum. 2020 Jul 23. 